\title{
Social Attitudes to Suicide and Suicide Rates
}

\author{
Saxby Pridmore ${ }^{1}$, Svetlin Varbanov ${ }^{2}$, Ivan Aleksandrov ${ }^{2}$, Said Shahtahmasebi ${ }^{3,4^{*}}$ \\ ${ }^{1}$ School of Medicine, University of Tasmania, Hobart, Tasmania, Australia \\ ${ }^{2}$ Medical University, Varna, Bulgaria \\ ${ }^{3}$ The Good Life Research Centre Trust, Christchurch, New Zealand \\ ${ }^{4}$ Community Faculty, University of Kentucky, Lexington, KY, USA \\ Email: ^radisolevoo@gmail.com
}

How to cite this paper: Pridmore, S., Varbanov, S., Aleksandrov, I. and Shahtahmasebi, S. (2016) Social Attitudes to Suicide and Suicide Rates. Open Journal of Social Sciences, 4, 39-58.

http://dx.doi.org/10.4236/jss.2016.410004

Received: September 27, 2016

Accepted: October 15, 2016

Published: October 18, 2016

Copyright $\odot 2016$ by authors and Scientific Research Publishing Inc. This work is licensed under the Creative Commons Attribution International License (CC BY 4.0).

http://creativecommons.org/licenses/by/4.0/

\begin{abstract}
Background: Persistence with ineffective suicide prevention together with suicide mortality trends are a concerning commentary on society. Although suicides are committed by individuals, the reasons for individuals contemplating suicide may, at least in part, be due to the socio-economic and socio-political perceptions and attitudes of suicide. A lack of public discussion and suicide education maintains current suicide trends and has led to "more of the same" interventions. Suicide prevention programmes must break the cycle of providing the public with more medical intervention at higher costs in terms of lives lost and in monetary term, and instead, eradicate suicide as a solution. Methods: In this paper we explore suicide as the outcome of a dynamic process of decision making, using the Predicament Questionnaire designed by one of the authors. Results: The results suggest that the association between adverse life events and suicide as a solution is well established in the public mindset. In other words, social perception of suicide as a solution to a problem can help maintain or raise suicide rates. Conclusions: Suicide must be openly and responsibly debated to remove the myth and stigma surrounding it. We recommend the grassroots approach to suicide prevention. Further research in replicating the survey questionnaire is needed.
\end{abstract}

\section{Keywords}

Predicament Questionnaire, Suicide Attitudes, Social Perceptions

\section{Introduction}

Suicide is one of the most researched causes of human mortality. However, despite the huge volume of suicide literature, other than mortality statistics, very little is understood about suicide. The literature seeks scientific evidence to explain suicide, but the 
science behind the evidence used to develop suicide prevention is flawed and unsustainable which contribute to the patterns in suicide trends over the last few decades (e.g. see [1]-[3]). Indeed, inevitably, the World Health Organisation published a document with a section dedicated to the myths about suicide and rejecting them including mental illness as the cause of suicide [4].

The main problem with suicide prevention has been the attempt to quantify suicide [5] rather than understand it. In other words, research has attempted to equate suicide to a cause, namely disorder of the mind. The current dominant medical model approach to suicide prevention assumes and interprets the cause as mental illness or disorder and therefore has transformed suicide prevention into suicide intervention [6].

Even those arguing for alternatives to the medical model seek non-clinical causes which for all intents and purposes offer no more benefit than the medical model. For example, a social model suggests bereavement, unemployment, divorce/breakup, failure, and so on may cause suicide. This is no different to the medical model argument that such events lead to depression and depression leads to suicide. Indeed, most suicide research aims to measure the depression levels in a particular group and then rank that group as high (or low) suicide risk group (e.g. see [7]-[19]). Unfortunately, such models have not contributed to suicide prevention and may in fact have exacerbated the suicide problem.

An alternative approach is to acknowledge our lack of understanding of suicide per se, and rather than assuming "mind" being ill as the cause of suicide, we could reinterpret the "mind" process of decision making. In this context, whilst we may not understand suicide, the process of decision making is better understood. Clear advantages of this approach are that suicide will be viewed as the outcome of a decision making process and suicide prevention policies will concentrate on removing suicide as an "off the "shelf" solution to problems. In contrast, a medical model assumes the presence of a mental disorder, which may or may not exist, and attempts to remove it from the suicide equation. This approach does not prevent suicide because suicide and mental illness are NOT one and the same [20]. Indeed, data from psychiatric hospitals demonstrated that patients being treated for suicidal behaviour went ahead and completed suicide whilst under psychiatric care and after being discharged [21].

Clearly, the decision making process is itself a function of other social, economic, health, environmental, and educational processes. However, the outcome of a decision depends also on social perceptions and attitudes that may make the outcome acceptable. Therefore, using this approach we must also gain insight into the social conscious of a community/society/nation.

In this paper, using data from a pilot study, we attempt to explore decision making process at the population level and discuss ramifications for suicide research and the process of developing suicide prevention policies.

\section{Methodology}

This study was approved by the ethics committee of the Medical University of Varna, 
Bulgaria.

Our aim was to explore any connection between individuals' and social perception of suicide, and whether the process of decision making is influenced by suicidal attitude when faced with an adverse life events, which we refer to as predicaments.

Different individuals react to predicaments differently. For example, individuals with similar characteristics facing the same predicament-one may contemplate suicide whilst others do not. In other words, differentials in outcome (whether or not the individuals act out their suicidal ideations) may well be due to unobserved heterogeneity in individuals (individual specific trait) and their culture (community/society specific trait). In this context, the severity of the predicaments is used to explore the threshold at which point a predicament may be viewed as a suicide trigger by respondents.

\section{The Predicament Questionnaire}

The Predicament Questionnaire [22] was designed by one of the authors (Pridmore) in order to explore public's attitudes and perceptions of suicide. The questionnaire is listed in the appendix and presents the respondents with a number of adverse life events, at various levels of severity. The questionnaire invites respondents to agree or disagree whether each event may be considered a trigger for contemplating suicide. This questionnaire presents 32 vignettes (predicaments) and asks respondents whether depicted individuals might experience suicidal thoughts, and if so, to what degree, using a slight, moderate, strong scale. Responders are encouraged "to focus on the typical responses of people in your community/culture", and advised, "Strong suicidal thoughts are those which could (but not necessarily) result in suicidal actions (fatal or nonfatal)".

The questionnaire was piloted on the internet. An invitation to complete the questionnaire was distributed in different countries around the world via the internet. Friends and colleague placed it on Facebook pages. Invitations were offered to Police Forces, Universities, Council Members, and Clubs which made email addresses publicly available.

\section{Results}

The pilot study resulted in 647 completed questionnaires (see appendix). There were responses from a total of 35 countries. The majority were from English speaking nations, however, making cross-cultural comparisons limited to Western style cultures, namely, Australia, US, UK, Canada, Ireland and New Zealand.

Respondents were asked to express their agreement with statements from each question on a Likert type agree/disagree scale (None $=1$, Slight $=2$, Moderate $=3$, and Strong $=4$ ). Thus, the range of values for each question is $1-4$, and the range across the 32 questions is 32 - 128. The assumption is that the 32 item questionnaire forms a sliding scale on which attitude to suicide may be measured, i.e. lower values on the scale indicates disagreement whilst higher values indicate various levels agreement with suicidal behaviour due to adversity. 
As shown in Figure 1, the scale appears fairly normally distributed with mean 68.51 and standard deviation of 16.3. Arbitrarily one standard deviation and the mean were chosen as cut off points to create a categorical scale for the purpose of cross-tabulation. Specifically, values below one standard deviation were grouped as "low" 1) those values between one standard and one point below the mean were grouped as "low moderate" 2 ) values one point either side and including the mean were grouped as "moderate" 3 ) values between one point above the mean and one standard deviation above the mean were grouped as "high moderate" 4) and values over one standard deviation were grouped as "high". The distribution of this new variable is shown in Table 1.

For the questions to be useful as a measure of individuals' and population attitudes/ perception to suicide, and add insight into the process of decision making, they must illustrate sensitivity of outcomes due to change of severity in life adversity.

The Questionnaire was designed as a means of quantifying suicidal attitude and suicidal thought induction. Under the theory of cognitive resonance [23] individuals upgrade or downgrade their decisions based on competing experiences and additional insight. In doing this survey respondents were subjected to changing scenarios which progressively increased the complexities and severity of life events. The question is whether the suicide attitude scale is sensitive enough to the thought process of the respondents. In other words, did level of severity of an adverse life event have an impact on the respondents answer to shift attitudes toward suicide? And, is this questionnaire sensitive enough to pick up respondents' re-evaluation and change of decision?

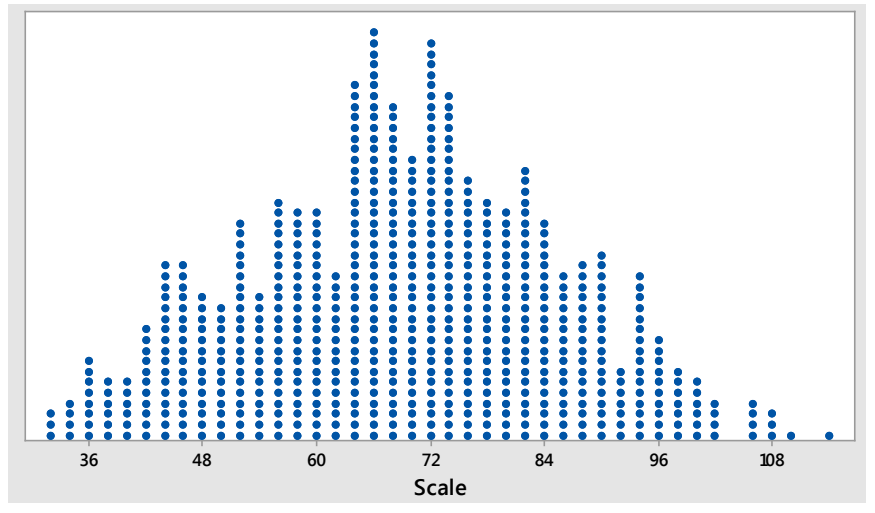

Figure 1. Scatter plot of suicide attitude scale.

Table 1. Distribution of the categorical suicide attitude scale.

\begin{tabular}{ccc}
\hline Attitude to Suicide & Frequency & Percent \% \\
\hline Low & 120 & 18.55 \\
Moderate below average & 185 & 28.59 \\
Average & 44 & 6.8 \\
Moderate above average & 192 & 29.68 \\
High & 106 & 16.38 \\
Total & 647 & 100 \\
\hline
\end{tabular}


These scenarios or predicaments together with their frequency distributions are shown in the appendix. It can be noticed that respondents' agreement with a suicidal ideation appears to be influenced by emotional complexity and severity of the scenario. For example, given the first predicament (Q1) where the breakup of a relationship is relatively simple over two-thirds of respondents disagreed with suicidal ideation and just under one-third agreed slightly, about $4 \%$ agreed moderately, and only $0.46 \%$ agreed strongly. These proportions change markedly when complexity is added to the relationship in the second predicament (Q2). The proportion who strongly agreed with suicidal ideation increases to $10 \%$ in Q3 when the added complexities are marital status and length married.

Similarly, when emotions are added to the mix, as in the case of an individual causing a fatal accident by breaking the law (e.g. driving drunk), it is less likely for the respondent(s) to empathise/sympathise with the fictitious case than if it were a random accident. This case is illustrated in Q4 and Q5, where in Q5the proportion of respondents who believe person $\mathrm{C}$ would have suicidal thought is more than double that of question 4 , row 4 and column 4 in Table 2 (also see appendix).

As shown in Table 2, the Questionnaire appears to be sensitive to the dynamics of decision making (re-evaluating previous decision and upgrading/downgrading it). It can be seen that when presented with an alternative adversity the majority changed their position but by one step to the next point on the scale. For example, of those who disagreed in Q4, 43 did not change their position in Q5, of the remainder 66 changed their position to slightly agree, 29 changed to moderately agree and 8 changed to strongly agree. The embolded numbers diagonally across the Table are those who did not change their mind following the change in scenario.

On the other hand, proportions who agree with suicidal thoughts appear to increase rapidly when emotion is added to the complexity of a predicament. For example, Table 3 shows the result for crossing Q1 with Q20; of the 438 respondents who disagreed in Q1 only 110 did not change their position in Q20, whilst the remainder changed their position as follows: 200 slightly agreed, 97 moderately agreed, and 31 strongly agreed. The numbers shown diagonally are those respondents who did not change their position in both scenarios (Q1 \& Q20). Conversely, downgrading of a choice is also possible. For example, 22 respondents who voted slight agreement and 13 respondents who voted moderate agreement in Q1 voted disagreement and slight disagreement respectively in Q20.

Similarly, in predicament 28 the inclusion of emotive family destitution is the added complexity. The result of crossing Q1 with Q28 is shown in Table 4. Once again it can be seen that there is an over-representation in the upper corner of Table 4 due to respondents switching agreement level in Q20 compared with Q1.

This pattern can be observed throughout the survey questionnaire, which provides evidence that this questionnaire can be used as a broad scale to measure attitudes to suicide. It is also reassuring that the result of a factor analysis confirms internal consistency and validity providing evidence for a single general scale [22]. 
Table 2. Result of cross-tabulation of Q4 with Q5.

\begin{tabular}{cccccc}
\hline \multirow{2}{*}{ Q4 } & \multicolumn{5}{c}{ Q5 } \\
\cline { 2 - 6 } & No & Slight & Moderate & Strong & Total \\
\hline No & $\mathbf{4 3}$ & 66 & 29 & 8 & 146 \\
Slight & 6 & $\mathbf{7 2}$ & 97 & 30 & 205 \\
Moderate & 3 & 7 & 101 & 93 & 204 \\
Strong & 0 & 0 & 4 & $\mathbf{8 8}$ & 92 \\
Total & 52 & 145 & 231 & 219 & 647 \\
\hline
\end{tabular}

Table 3. Result of cross-tabulation of Q1 with Q20.

\begin{tabular}{cccccc}
\hline & \multicolumn{5}{c}{ Q20 } \\
\cline { 2 - 5 } Q1 & No & Slight & Moderate & Strong & Total \\
\hline No & 110 & 200 & 97 & 31 & 438 \\
Slight & 22 & 69 & 68 & 16 & 175 \\
Moderate & 2 & 13 & 10 & 6 & 31 \\
Strong & 1 & 0 & 1 & 1 & 3 \\
Total & 135 & 282 & 176 & 54 & 647 \\
\hline
\end{tabular}

Table 4. Result of cross-tabulation of Q1 with Q28.

\begin{tabular}{cccccc}
\hline & \multicolumn{5}{c}{ Q28 } \\
\cline { 2 - 6 } Q1 & No & Slight & Moderate & Strong & Total \\
\hline No & $\mathbf{8 5}$ & 130 & 147 & 76 & 438 \\
Slight & 6 & 41 & 68 & 60 & 175 \\
Moderate & 2 & 7 & 10 & 12 & 31 \\
Strong & 1 & 1 & 0 & 1 & 3 \\
Total & 94 & 179 & 225 & 149 & 647 \\
\hline
\end{tabular}

\section{Discussion of Applications/Implications of the Questionnaire}

Clearly, a scale that can quantify suicidal attitudes at individual and aggregate/population levels will have implications for research and suicide prevention development. As an example we carried out a number of comparisons. Table 5 illustrates comparisons at individual predicament level by age and gender. A similar pattern can be observed across the age range for males and females. However, there is some evidence to suggest that males in this sample underestimate and females overestimate association between a predicament and suicidal thoughts. In Table 5, the proportion of females who disagreed and slightly agreed in Q4 was significantly reduced in Q5 while the proportion who moderately agreed did not change and the proportion who agreed strongly more than doubled. For male respondents, the proportion of those who moderately agreed also significantly increased which suggests that males may be more conservative in their decision making. 
Table 5. Comparison of Q4 \& Q5 across age by gender.

\begin{tabular}{|c|c|c|c|c|c|c|c|c|c|}
\hline \multirow{2}{*}{ Age } & \multicolumn{4}{|c|}{ Females: Q4 } & \multirow{2}{*}{ Total } & \multicolumn{4}{|c|}{ Females: Q5 } \\
\hline & No & Slight & Moderate & Strong & & No & Slight & Moderate & Strong \\
\hline $15-24$ & 24 & 37 & 57 & 33 & 151 & 9 & 25 & 51 & 66 \\
\hline $25-34$ & 12 & 28 & 27 & 10 & 77 & 5 & 14 & 29 & 29 \\
\hline $35-44$ & 19 & 17 & 11 & 8 & 55 & 6 & 15 & 19 & 15 \\
\hline $45-54$ & 11 & 16 & 13 & 7 & 47 & 4 & 17 & 9 & 17 \\
\hline $55-64$ & 6 & 9 & 13 & 6 & 34 & 6 & 5 & 10 & 13 \\
\hline $65+$ & 2 & 3 & 4 & 2 & 11 & 2 & 1 & 6 & 2 \\
\hline Total & 74 & 110 & 125 & 66 & 375 & 32 & 77 & 124 & 142 \\
\hline \multicolumn{6}{|c|}{ Males: Q4 } & \multicolumn{4}{|c|}{ Males: Q5 } \\
\hline $15-24$ & 30 & 32 & 38 & 11 & 111 & 4 & 22 & 49 & 36 \\
\hline $25-34$ & 13 & 27 & 21 & 8 & 69 & 5 & 16 & 25 & 23 \\
\hline $35-44$ & 7 & 14 & 9 & 2 & 32 & 5 & 7 & 14 & 6 \\
\hline $45-54$ & 11 & 6 & 5 & 1 & 23 & 1 & 11 & 7 & 4 \\
\hline $55-64$ & 3 & 11 & 1 & 2 & 17 & 1 & 5 & 7 & 4 \\
\hline $65+$ & 6 & 5 & 1 & 0 & 12 & 2 & 6 & 3 & 1 \\
\hline Total & 70 & 95 & 75 & 24 & 264 & 18 & 67 & 105 & 74 \\
\hline
\end{tabular}

Note: the cell frequency for gender other than male/female was too small (below 10).

Another example is provided Table $6 \&$ Table 7 demonstrating differentials in attitudes to suicide due to age and gender, and country of residence, respectively at population level. Table 6 shows the descriptive analysis of the suicide attitude scale broken down by gender and age. It can be seen that on average the variations in suicide attitudes scores for females of all ages appear to be wider than males as shown by the score range (minimum, maximum). It can also be seen that males mean score appears lower than that for females, however, this difference is not statistically significant $(\mathrm{p}=0.66)$. Fewer than 9 respondents described their gender as "other" which is too small to be included in the analysis.

Table 7 shows the suicide attitude scores by country of residence. In this table only those countries from which there were more than 15 respondents are listed. Low scores are indicative of aggregate sample disagreement of suicide being a solution to a problem, conversely moderate and high scores indicative of acceptance of suicide as a solution. However, we emphasise that caution must be exercised and results cannot be generalised to the population, as further research is necessary. We can, however, limit inference to the sample of respondents from each country. Having said that, we can compare suicide attitude scores between countries contrasted against each country's suicide rate shown in Table 8. For example, UK's suicide rate is the lowest amongst the countries listed, which appears to coincide with lower values than other countries in the high categories of the suicide attitude score, and higher values in the low categories of the suicide attitude score. This result is reassuringly consistent with the higher scores on the suicide attitude scale to be indicative of acceptance of suicide as a solution to problems. 
Table 6. A descriptive comparison of male/female's suicide score across age.

\begin{tabular}{ccccccccc}
\hline \multirow{2}{*}{ Age } & \multicolumn{9}{c}{ Females } & \multicolumn{5}{c}{ Males } \\
\cline { 2 - 8 } & $\mathrm{N}$ & Mean & S.D & Range & $\mathrm{N}$ & Mean & S.D & Range \\
\hline $15-24$ & 151 & 71.92 & 16.20 & $34-107$ & 111 & 68.81 & 14.37 & $36-97$ \\
$25-34$ & 77 & 66.74 & 15.89 & $32-105$ & 69 & 69.65 & 16.54 & $36-113$ \\
$35-44$ & 55 & 64.71 & 16.43 & $34-98$ & 32 & 64.34 & 14.42 & $38-96$ \\
$45-54$ & 47 & 63.15 & 15.82 & $32-102$ & 23 & 66.00 & 18.33 & $36-106$ \\
$55-64$ & 11 & 74.09 & 25.61 & $32-107$ & 12 & 59.58 & 13.01 & $43-84$ \\
$65+$ & 34 & 71.71 & 18.99 & $33-108$ & 17 & 69.82 & 13.02 & $42-94$ \\
\hline
\end{tabular}

Table 7. Respondents' suicide attitude by their country of residence.

\begin{tabular}{ccccccc}
\hline \multirow{2}{*}{ Country } & \multicolumn{5}{c}{ Categorised Suicide Scale } & \multirow{2}{*}{ Total } \\
\cline { 2 - 5 } & Low & Low moderate & Moderate & High moderate & High & \\
\cline { 2 - 5 } Australia & 46 & 69 & 19 & 70 & 20 & 224 \\
& $20.5 \%$ & $30.8 \%$ & $8.5 \%$ & $31.3 \%$ & $8.9 \%$ & $100 \%$ \\
Canada & 9 & 15 & 3 & 12 & 7 & 46 \\
& $19.6 \%$ & $32.6 \%$ & $6.5 \%$ & $26.1 \%$ & $15.2 \%$ & $100 \%$ \\
Ireland & 8 & 13 & 3 & 12 & 13 & 49 \\
& $16.3 \%$ & $26.5 \%$ & $6.12 \%$ & $24.5 \%$ & $26.5 \%$ & $100 \%$ \\
New Zealand & 15 & 19 & 3 & 21 & 14 & 72 \\
& $20.8 \%$ & $26.4 \%$ & $4.2 \%$ & $29.2 \%$ & $19.4 \%$ & $100 \%$ \\
UK & 9 & 13 & 4 & 7 & 8 & 41 \\
& $22 \%$ & $31.8 \%$ & $9.8 \%$ & 17.1 & $19.5 \%$ & $100 \%$ \\
USA & 18 & 32 & 8 & 46 & 33 & 137 \\
& $13.1 \%$ & $23.4 \%$ & $5.8 \%$ & $33.6 \%$ & $24.1 \%$ & $100 \%$ \\
Total & 108 & 163 & 42 & 173 & 97 & 583 \\
& $18.5 \%$ & $28 \%$ & $7.2 \%$ & $29.7 \%$ & $16.6 \%$ & $100 \%$ \\
\hline
\end{tabular}

Table 8. Suicide death rates by OECD country.

\begin{tabular}{cccccc}
\hline Country & 2009 & 2010 & 2011 & 2012 & 2013 \\
\hline Australia & 10.7 & 10.9 & 10.1 &.. &.. \\
Canada & 11.1 & 11.2 & 10.5 &.. &.. \\
Ireland & 11.7 & 11.0 &.. &.. &.. \\
New Zealand & 12.0 & 12.4 & 11.3 &.. &.. \\
United Kingdom & 6.8 & 6.7 & 6.9 & 7.0 & 7.6 \\
United States & 12.1 & 12.5 &.. &.. &..
\end{tabular}

1. Age-standardised death rates per 100,000 population for intentional self-harm are calculated by the OECD Secretariat, using the total OECD population for 2010 as the reference population.

Symbol:

...figure not available

Source: OECD Health data (sourced from the World Health Organisation Mortality Database) 
It is interesting that, after decades of suicide prevention, suicide is still viewed as an "off the shelf" option to problems, which is also evident from qualitative data collected in this pilot study. Out of the 647 respondents 133 chose to leave a comment. Almost all comments were from English speaking countries. One commented that suicide is rare in their culture because of religion, which may represent the Middle Eastern cultures' view of suicide. Only one or two made direct or indirect comment about suicide being wrong and not a solution to problems, the rest commented that more information was needed as they believed suicide or suicidal ideations depended on other factors such as personal traits and the nature of relationships, as evident by the following comments:

"I found these questions difficult to anticipate the answer without knowing the people. Answered them as best I could."

"Some questions hard to answer others I have known of friends and colleagues who have killed themselves Thought provoking questionnaire."

"Depression/suicidal thoughts are also considered signs of a mental disorder so..."

"This survey was very thought provoking and it was difficult at times to put my mind in some situations but overall it raised the many reasons why an individual could potentially commit suicide and is important to take on board."

"I am, as an individual, happily NOT prone to suicidal thoughts or tendencies. Nonetheless, my answers are meant to reflect those of my entourage rather than my own (which would have tended more to the "No"). For example, while I recognize that throughout society event such as that described in $25 \mathrm{do}$, in fact, lead to rashes of suicides, the vast majority of people in my community/society did not even consider such a response themselves."

"I have stated no for all answers as I do not know what others would feel I only know what I feel."

"I found it difficult to answer these questions because everyone responds differently to life stressors."

"I have answered how I would feel, and most of the people I know, even though my brother in law committed suicide and my sister tried twice to commit suicide, and after taking medication for depression my daughter who had never thought about suicide before started to want to commit suicide but for none of the reasons above."

"I have previously suffered from "suicidal ideation". Often it was all-consuming for days at a time. At the time, I had the world's most wonderful job (airline pilot), was financially secure and had a loving and healthy family (including grandchildren). There was no single trigger but a series of minor stresses contributed to my eventual early retirement and treatment (medication and counselling). Some of the triggers were unfair treatment by a manager, the prospect of retirement emphasising the advancing age, loss of an elderly parent, movement of place of residence, and the breakdown of a long-term friendship. However, I believe that an early career in the RAAF flying jets and helicopters which, by their very nature, involved some serious incidents and the witnessing of several deaths and the aftermath, 
probably laid the seeds for future breakdown. In the 1970s, there was not posttraumatic counselling except to go to the bar and get horribly drunk-and fly again the next morning. I hope this helps with your research I am happy to talk about my experiences if you require more information."

"I have answered the questions but acknowledge that in many instances only some members of my community would react in a particular way. In any situation different people will react differently and other factors will influence this."

"I found these questions difficult to anticipate the answer without knowing the people. Answered them as best I could."

"If there wasn't such a stigma against suicide, then maybe those with depression would be able to say goodbye to their friends and family before killing themselves. Instead they die alone in secret. There is only so long someone suffering true depression can fight it for. It shouldn't be something to be ashamed about, and rarely spoken about."

\section{Limitations}

The main pitfalls of restricting a dynamic process by quantifying it into a single scale are lumping variations, due to different sources, into one leading to loss of information. A single scale does not allow distinguishing between anger, empathy, sympathy at individuals' and social level. Furthermore, such quantification of suicide attitudes does not provide a measure of individuals' own suicidal ideation. On the other hand, the scale may be used to explore social and population suicidal attitudes. We have restricted inference to the pilot study's sample only.

\section{Conclusions}

More research is necessary to develop this scale into a multidimensional scale, e.g. by exploring individuals' perceptions and beliefs further. Another dimension could be added to the questionnaire on individuals' knowledge of suicide and its statistics such as morbidity/mortality, reason(s) for interest in suicide/this survey, any direct or indirect experience with suicide and suicide prevention, have they been asked for help, do they know how to respond to requests for help from family, friends or strangers, how do they believe their community/society/country view suicide, is there a healthy suicide debate/education in their community, is suicide education medically based.

In summary there are two areas of interest from the initial descriptive analysis of data from the Predicament Questionnaire, first, the attenuation of perception of suicide in the public mindset, second, there may be a link between public's perception of suicide and suicide rates. These are important and interesting results and will have implications for suicide prevention policy development.

This suicide attitude questionnaire provides evidence to support the view that "suicide is a solution to problems" has been normalised. In other words, suicide prevention policies have become part of the suicide problem. It is imperative to de-normalise suicide as a solution to a problem. To achieve this, suicide prevention policy must learn to 
prevent suicide as opposed to wait for suicidal behaviour to develop and then attempt to intervene. To prevent suicide, a cultural shift that eliminates the social perception of suicide as the answer to life problems and adversity is necessary [24]. This cultural shift was achieved by the grassroots approach to suicide prevention reducing suicide down to zero in the participating communities [25].

We do not yet properly understand suicide. We do not question "why" but are happy to persist with efforts at suicide prevention through the management of mental illness.

Future suicide research must address suicide as the concerning commentary on our societies, i.e. the outcome of a dynamic decision making process, and ask the question why suicide is viewed as the solution to problems?

\section{Acknowledgements}

The authors received no funds and have no conflicts of interest.

\section{References}

[1] Hjelmeland, H., Dieserud, G., Dyregrov, K., Knizek, B.L. and Leenaars, A.A. (2012) Psychological Autopsy Studies as Diagnostic Tools: Are They Methodologically Flawed? Death Studies, 36, 605-626. http://dx.doi.org/10.1080/07481187.2011.584015

[2] Shahtahmasebi, S. (2005) Suicides in New Zealand. Scientific World Journal, 5, 527-534. http://dx.doi.org/10.1100/tsw.2005.74

[3] Shahtahmasebi, S. (2014) Suicide Research: Problems with Interpreting Results. British Journal of Medicine and Medical Research, 5, 1147-1157. http://dx.doi.org/10.9734/BJMMR/2015/12802

[4] WHO (2014) Preventing Suicide: A Global Imperative. http://www.who.int/mental_health/suicide-prevention/world_report_2014/en/

[5] White, J., et al. (2016) Critical Suicidology: Transforming Suicide Research and Prevention for the 21st Century. UBC, Toronto.

[6] Moscicki, E. (1997) Identification of Suicide Risk Factors Using Epidemiologic Studies. Psychiatric Clinics of North America, 20, 499-517. http://dx.doi.org/10.1016/S0193-953X(05)70327-0

[7] Ainiyet, J. and Rybakowski, J. (1996) [Low Concentration Level of Total Serum Cholesterol as a Risk Factor for Suicidal and Aggressive Behavior]. Psychiatria Polska, 30, 499-509.

[8] Brunner, J., Parhofer, K.G., Schwandt, P. and Bronisch, T. (2002) Cholesterol, Essential Fatty Acids, and Suicide. Pharmacopsychiatry, 35, 1-5. http://dx.doi.org/10.1055/s-2002-19834

[9] Dancyger, I.F. and Fornari, V.M. (2005) A Review of Eating Disorders and Suicide Risk in Adolescence. The Scientific World Journal, 5, 803-811. http://dx.doi.org/10.1100/tsw.2005.101

[10] Farley, R.L. (2005) Pharmacological Treatment of Major Depressive Disorder in Adolescents. The Scientific World Journal, 5, 420-426. http://dx.doi.org/10.1100/tsw.2005.55

[11] Latzer, Y. and Hochdorf, Z. (2005) A Review of Suicidal Behaviour in Anorexia Nervosa. The Scientific World Journal, 5, 820-827. http://dx.doi.org/10.1100/tsw.2005.95

[12] Maharajh, H.D. and Konings, M. (2005) Cannabis and Suicidal Behaviour among Adolescents: A Pilot Study from Trinidad. The Scientific World Journal, 5, 576-585. http://dx.doi.org/10.1100/tsw.2005.79 
[13] Merrick, J., Merrick, E., Lunsky, Y. and Kandel, I. (2005) Suicide Behaviour in Persons with Intellectual Disability. The Scientific World Journal, 5, 729-735.

http://dx.doi.org/10.1100/tsw.2005.91

[14] Pompili, M., et al. (2006) Suicide Soon after Generalizd Tonic-Clonic Seizure. A Possible Peri-Ictal Phenomenon? The Scientific World Journal, 6, 356-360.

http://dx.doi.org/10.1100/tsw.2006.72

[15] Postolache, T.T., et al. (2007) Changes in Allergy Symptoms and Depression Scores Are Positively Correlated in Patients with Recurrent Mood Disorders Exposed to Seasonal Peaks in Aeroallergens. The Scientific World Journal, 7, 1968-1977. http://dx.doi.org/10.1100/tsw.2007.286

[16] Sher, L. (2006) Risk and Protective Factors for Suicide in Patients with Alcholism. The Scientific World Journal, 6, 1405-1411. http://dx.doi.org/10.1100/tsw.2006.254

[17] Cassem, E.H. (1995) Depressive Disorders in the Medically Ill. An Overview. Psychosomatics, 36, S2-S10. http://dx.doi.org/10.1016/s0033-3182(95)71698-x

[18] Schulz, R., Drayer, R.A. and Rollman, B.L. (2002) Depression as a Risk Factor for NonSuicide Mortality in the Elderly. Biological Psychiatry, 52, 205-225. http://dx.doi.org/10.1016/S0006-3223(02)01423-3

[19] Mann, J.J., et al. (2005) Suicide Prevention Strategies: A Systematic Review. JAMA, 294, 2064-2074. http://dx.doi.org/10.1001/jama.294.16.2064

[20] Shahtahmasebi, S. and Smith, L. (2013) Has the Time Come for Mental Health Services to Give up Control? Journal of Alternative Medicine Research, 6, 9-17.

[21] Shahtahmasebi, S. (2003) Suicides by Mentally Ill People. The Scientific World Journal, 3, 684-693. http://dx.doi.org/10.1100/tsw.2003.51

[22] Varbanov, S., Aleksandrov, I. and Pridmore, S. (2016) Predicaments Ranked by Quantity of Induced Suicidal Thoughts, Using the Pridmore-Varbanov Questionnaire. Working Paper, Department of Psychiatry, Medical University of Varna, Bulgaria,

[23] McGinnis, R. (1968) A Stochastic Model of Social Mobility. American Sociological Review, 23, 712-722. http://dx.doi.org/10.2307/2092882

[24] Pridmore, S. and Walter, G. (2013) Culture and Suicide Set Points. German Journal of Psychiatry, 16, 143-151.

[25] Shahtahmasebi, S. (2013) De-Politicizing Youth Suicide Prevention. Frontiers in Pediatrics, 1, 8. http://journal.frontiersin.org/article/10.3389/fped.2013.00008/abstract http://dx.doi.org/10.3389/fped.2013.00008 


\section{Appendix}

\section{The Predicament questionnaire}

Gender $($ Males $=264$, Females $=375$, Other $=8)$

Age bracket

$\begin{array}{lc}15-24 \text { years } & 268 \\ 25 \text { - 34 years } & 146 \\ 35 \text { - 44 years } & 87 \\ 45 \text { - 54 years } & 70 \\ 55 \text { - 64 years } & 52 \\ 65 \text { years and above } & 24 \\ \mathrm{~N}= & 647\end{array}$

Country, and region/state/canton/prefecture

Australia $\quad 224$

Canada 46

Ireland 49

New Zealand $\quad 72$

UK 41

USA $\quad 137$

$\mathrm{N}=\quad 583$

$* \quad 78$

The suicide attitude Scale:

Respondents were asked answer the following questions using a Likert type agree/ disagree scale: $1=$ No, $2=$ Slight, $3=$ Moderate, $4=$ Strong.

1) Person $A$ had a romantic relationship of about 1 year, with person $B$, but they had not been living together. Person $B$ ended the relationship and commenced a new relationship with a third person.

Would person A have suicidal thoughts?

$\begin{array}{clll}\text { Sample frequency distribution: } & \text { Q1 } & \text { Count } & \text { Percent } \\ 1 & 438 & 67.70 \\ 2 & 175 & 27.05 \\ 3 & 31 & 4.79 \\ 4 & 3 & 0.46 \\ \mathrm{~N}= & 647 & \end{array}$

2) Person A had a romantic relationship with person $B$ of about 1 year, and they had been living together. Person $B$ ended the relationship and commenced a new relationship with a third person.

Would person A have suicidal thoughts?

Sample frequency distribution: Q2 Count Percent

$1 \quad 306 \quad 47.30$

$2 \quad 34.62$

$\begin{array}{lll}3 & 98 & 15.15\end{array}$

$\begin{array}{lll}4 & 19 & 2.94\end{array}$




$$
\mathrm{N}=\quad 647
$$

3) Person A and Person B had been married for about 1 year. Person B ended the marriage and commenced a new relationship with a third person.

Would person A have suicidal thoughts?

$\begin{array}{clll}\text { Sample frequency distribution: } & \text { Q3 } & \text { Count } & \text { Percent } \\ 1 & 200 & 30.91 \\ 2 & 232 & 35.86 \\ 3 & 153 & 23.65 \\ 4 & 62 & 9.58 \\ \mathrm{~N}= & 647 & \end{array}$

4) Person $C$ was driving below the speed limit on a suburban street. A child ran onto the road. To avoid the child, person $\mathrm{C}$ swerved and killed an adult on the other footpath.

Would person C have suicidal thoughts?

$\begin{array}{clll}\text { Sample frequency distribution: } & \text { Q4 } & \text { Count } & \text { Percent } \\ 1 & 146 & 22.57 \\ 2 & 205 & 31.68 \\ 3 & 204 & 31.53 \\ 4 & 92 & 14.22 \\ \mathrm{~N}= & 647 & \end{array}$

5) Person $C$ attended a party and got drunk. In spite of advice not to drive, and the offer of being driven home by a friend, person $\mathrm{C}$ insisted on driving. Person $\mathrm{C}$ drove above the speed limit and hit and killed a pedestrian on a pedestrian crossing.

Would person $\mathrm{C}$ have suicidal thoughts?

Sample frequency distribution: Q5 Count Percent

$\begin{array}{lll}1 & 52 & 8.04 \\ 2 & 145 & 22.41 \\ 3 & 231 & 35.70 \\ 4 & 219 & 33.85 \\ \mathrm{~N}= & 647 & \end{array}$

6) Person D has heterosexual intercourse with Person Z. Without Person D's permission, this event is secretly filmed and placed on the web by a third person.

Would person D have suicidal thoughts?

Sample frequency distribution: Q6 Count Percent

$\begin{array}{lll}1 & 163 & 25.19 \\ 2 & 213 & 32.92 \\ 3 & 173 & 26.74 \\ 4 & 98 & 15.15 \\ \mathrm{~N}= & 647 & \end{array}$

7) Person D has homosexual intercourse with Person Y. Without Person D's permission, this event is secretly filmed and placed on the web by a third person.

Would person D have suicidal thoughts? 


$\begin{array}{llll}\text { Sample frequency distribution: } & \text { Q7 } & \text { Count } & \text { Percent } \\ 1 & 117 & 18.08 \\ 2 & 190 & 29.37 \\ 3 & 213 & 32.92 \\ 4 & 127 & 19.63 \\ \mathrm{~N}= & 647 & \end{array}$

8) Person E suffers spinal injuries and will be confined to a wheelchair for life.

Would person $\mathrm{E}$ have suicidal thoughts?

$\begin{array}{llll}\text { Sample frequency distribution: } & \text { Q8 } & \text { Count } & \text { Percent } \\ 1 & 24 & 3.71 \\ 2 & 136 & 21.02 \\ 3 & 257 & 39.72 \\ 4 & 230 & 35.55 \\ \mathrm{~N}= & 647 & \end{array}$

9) Person E develops a painful, terminal (will be fatal) disorder.

Would person E have suicidal thoughts?

Sample frequency distribution: Q9 Count Percent

$\begin{array}{lll}1 & 32 & 4.95 \\ 2 & 86 & 13.29 \\ 3 & 211 & 32.61 \\ 4 & 318 & 49.15 \\ \mathrm{~N}= & 647 & \end{array}$

10) Person F comes from a very high status and well educated family. Person F is convicted of stealing and jailed.

Would person $\mathrm{F}$ have suicidal thoughts?

$\begin{array}{llll}\text { Sample frequency distribution: } & \text { Q10 } & \text { Count } & \text { Percent } \\ 1 & 209 & 32.30 \\ 2 & 240 & 37.09 \\ 3 & 149 & 23.03 \\ 4 & 49 & 7.57 \\ \mathrm{~N}= & 647 & \end{array}$

11) Person F comes from a very high status and well educated family. Person F studies very hard, but lacks academic skills and at the end of a year at university, fails every subject.

Would person $\mathrm{F}$ have suicidal thoughts?

$\begin{array}{llll}\text { Sample frequency distribution: } & \text { Q11 } & \text { Count } & \text { Percent } \\ 1 & 176 & 27.20 \\ 2 & 212 & 32.77 \\ 3 & 173 & 26.74 \\ 4 & 86 & 13.29 \\ \mathrm{~N}= & 647 & \end{array}$

12) Person G comes from an average family. Person G is convicted of stealing and 
jailed.

Would person G have suicidal thoughts?

Sample frequency distribution: Q12 Count Percent

$1 \quad 265 \quad 40.96$

$2 \quad 275 \quad 42.50$

$3 \quad 94 \quad 14.53$

$4 \quad 13 \quad 2.01$

$\mathrm{N}=\quad 647$

13) Person G comes from an average family. Person G studies very hard, but lacks academic skills and at the end of a year at university, fails every subject.

Would person $\mathrm{G}$ have suicidal thoughts?

Sample frequency distribution: Q13 Count Percent

$\begin{array}{lll}1 & 237 & 36.63 \\ 2 & 255 & 39.41 \\ 3 & 112 & 17.31 \\ 4 & 43 & 6.65 \\ \mathrm{~N}= & 647 & \end{array}$

14) Person $\mathrm{H}$ and Person $\mathrm{X}$ lived in the same street as children and have been life-long, close friends. Person $\mathrm{H}$ is killed in a train crash.

Would person $\mathrm{X}$ have suicidal thoughts?

Sample frequency distribution: Q14 Count Percent

$\begin{array}{lll}1 & 371 & 57.34 \\ 2 & 175 & 27.05 \\ 3 & 78 & 12.06 \\ 4 & 23 & 3.55 \\ \mathrm{~N}= & 647 & \end{array}$

15) Person $H$ and Person $X$ lived in the same street as children and have been lifelong, close friends. Person $\mathrm{H}$ kills him/herself by standing in the path of a train.

Would person $\mathrm{X}$ have suicidal thoughts?

Sample frequency distribution: Q15 Count Percent

$\begin{array}{lll}1 & 293 & 45.29 \\ 2 & 197 & 30.45 \\ 3 & 106 & 16.38 \\ 4 & 51 & 7.88 \\ \mathrm{~N}= & 64 & \end{array}$

16) Person J dropped a gas bottle which exploded. Person J sustained severe burns to the face and hands, which left disfiguring scars.

Would person J have suicidal thoughts?

Sample frequency distribution: Q16 Count Percent

$\begin{array}{lll}1 & 122 & 18.86 \\ 2 & 232 & 35.86 \\ 3 & 216 & 33.38\end{array}$




$$
\begin{array}{lll}
4 & 77 & 11.90 \\
\mathrm{~N}= & 647 &
\end{array}
$$

17) Person $K$ developed a mental disorder which responds well to treatment, and does not cause Person $\mathrm{K}$ to lose more than 5 working days per year.

Would person $\mathrm{K}$ have suicidal thoughts?

Sample frequency distribution: Q17 Count Percent

$\begin{array}{lll}1 & 441 & 68.16 \\ 2 & 167 & 25.81 \\ 3 & 34 & 5.26 \\ 4 & 5 & 0.77 \\ \mathrm{~N}= & 647 & \end{array}$

18) Person $\mathrm{K}$ develops a mental disorder, which does not respond well to treatment, and Person $\mathrm{K}$ is no longer able to work.

Would person $\mathrm{K}$ have suicidal thoughts?

Sample frequency distribution: Q18

$\begin{array}{ll}1 & 37 \\ 2 & 166 \\ 3 & 269 \\ 4 & 175 \\ \mathrm{~N}= & 64\end{array}$

19) Person $K$ develops arthritis, which responds well to treatment, and does not cause Person $\mathrm{K}$ to lose more than 5 working days per year.

Would person $\mathrm{K}$ have suicidal thoughts?

Sample frequency distribution: Q19 Count Percent

$\begin{array}{lll}1 & 566 & 87.48 \\ 2 & 64 & 9.89 \\ 3 & 17 & 2.63 \\ \mathrm{~N}= & 647 & \end{array}$

20) Person K develops arthritis, which does not respond well to treatment, and Person $\mathrm{K}$ is no longer able to work.

Would person $\mathrm{K}$ have suicidal thoughts?

Sample frequency distribution: Q20 Count Percent

$\begin{array}{lll}1 & 135 & 20.87 \\ 2 & 282 & 43.59 \\ 3 & 176 & 27.20 \\ 4 & 54 & 8.35 \\ \mathrm{~N}= & 647 & \end{array}$

21) Person $L$ is a great fan of Person $M$, who is a popular singer, actor and talk-show celebrity. Person $\mathrm{M}$ dies when a building collapses.

Would person L have suicidal thoughts?

Sample frequency distribution: Q21 Count Percent

$1 \quad 575 \quad 88.87$




$\begin{array}{lll}2 & 59 & 9.12 \\ 3 & 11 & 1.70 \\ 4 & 2 & 0.31 \\ \mathrm{~N}= & 47 & \end{array}$

22) Person $L$ is a great fan of Person $M$, who is a popular singer, actor and talk-show celebrity. Person $\mathrm{M}$ dies by jumping from a building.

Would person $L$ have suicidal thoughts?

Sample frequency distribution: Q22 Count Percent

$\begin{array}{lll}1 & 429 & 66.31 \\ 2 & 180 & 27.82 \\ 3 & 35 & 5.41 \\ 4 & 3 & 0.46 \\ \mathrm{~N}= & 647 & \end{array}$

23) Person N's parent has committed a serious crime. Person $\mathrm{N}$ is aware of the facts. Person $\mathrm{N}$ has been subpoenaed to appear in court and will be asked questions under oath, which will probably lead to the parent being convicted and receiving a jail sentence.

Would person $\mathrm{N}$ have suicidal thoughts?

Sample frequency distribution: Q23 Count Percent

$\begin{array}{lll}1 & 318 & 49.15 \\ 2 & 209 & 32.30 \\ 3 & 99 & 15.30 \\ 4 & 21 & 3.25 \\ \mathrm{~N}= & 647 & \end{array}$

24) Person $O$ is in love with Person P, but person O's parents want Person O to marry a third person, of their choosing.

Would person $\mathrm{O}$ have suicidal thoughts?

Sample frequency distribution: Q24 Count Percent

$\begin{array}{lll}1 & 334 & 51.62 \\ 2 & 198 & 30.60 \\ 3 & 90 & 13.91 \\ 4 & 25 & 3.86 \\ \mathrm{~N}= & 647 & \end{array}$

25) Person $Q$ has a serious gambling problem, has lost the family's savings and is in debt. Bills are starting to arrive which cannot be easily paid.

Would person Q have suicidal thoughts?

Sample frequency distribution: Q25 Count Percent

$\begin{array}{lll}1 & 82 & 12.67 \\ 2 & 238 & 36.79 \\ 3 & 228 & 35.24 \\ 4 & 99 & 15.30 \\ \mathrm{~N}= & 647 & \end{array}$


26) Person $Q$ has a serious gambling problem, has lost the family's savings and is deeply in debt. Person Q's family is about to be turned out onto the street by debt collectors.

Would person Q have suicidal thoughts?

Sample frequency distribution: Q26 Count Percent

$\begin{array}{lll}1 & 53 & 8.19 \\ 2 & 133 & 20.56 \\ 3 & 219 & 33.85 \\ 4 & 242 & 37.40 \\ \mathrm{~N}= & 647 & \end{array}$

27)Person $R$ cannot find work and is having trouble paying the family bills.

Would person $\mathrm{R}$ have suicidal thoughts?

Sample frequency distribution: Q27 Count Percent

$\begin{array}{lll}1 & 185 & 28.59 \\ 2 & 284 & 43.89 \\ 3 & 136 & 21.02 \\ 4 & 42 & 6.49 \\ \mathrm{~N}= & 647 & \end{array}$

28) Person R cannot find work and the family is destitute. Person R's family is about to be turned out onto the street by debt collectors.

Would person $\mathrm{R}$ have suicidal thoughts?

Sample frequency distribution: Q28 Count Percent

$\begin{array}{lll}1 & 94 & 14.53 \\ 2 & 179 & 27.67 \\ 3 & 225 & 34.78 \\ 4 & 149 & 23.03 \\ \mathrm{~N}= & 647 & \end{array}$

29) Person $S$ has a 3 year old child with terminal (will be fatal) cancer.

Would person $S$ have suicidal thoughts?

Sample frequency distribution: Q29 Count Percent

$1 \quad 315 \quad 48.69$

$2 \quad 155 \quad 23.96$

$3 \quad 109 \quad 16.85$

$\begin{array}{lll}4 & 68 & 10.51\end{array}$

$\mathrm{N}=\quad 647$

30) Person $U$ is convicted of rape and murder, and has been sentenced to life in jail without parole.

Would person $\mathrm{U}$ have suicidal thoughts?

Sample frequency distribution: Q30 Count Percent

$1 \quad 129 \quad 19.94$

$2 \quad 135 \quad 20.87$

$3 \quad 195 \quad 30.14$


31) Person V is the spouse of Person $U$ (the rapist-murderer in question 33).

Would person $\mathrm{V}$ have suicidal thoughts?

$\begin{array}{clll}\text { Sample frequency distribution: } & \text { Q31 } & \text { Count } & \text { Percent } \\ 1 & 207 & 31.99 \\ 2 & 208 & 32.15 \\ 3 & 167 & 25.81 \\ 4 & 65 & 10.05 \\ \mathrm{~N}= & 647 & \end{array}$

32) Person $W$ had always been popular. However, since winning a prize, Person $W$ has been subjected to a sustained, malicious web campaign, including accusations of conceit, sexual deviance and dishonest acts.

Would person $\mathrm{W}$ have suicidal thoughts?

$\begin{array}{clll}\text { Sample frequency distribution: } & \text { Q32 } & \text { Count } & \text { Percent } \\ 1 & 14 & 22.87 \\ 2 & 255 & 39.41 \\ 3 & 179 & 27.67 \\ 4 & 65 & 10.05 \\ \mathrm{~N}= & 647 & \end{array}$

Submit or recommend next manuscript to SCIRP and we will provide best service for you:

Accepting pre-submission inquiries through Email, Facebook, LinkedIn, Twitter, etc. A wide selection of journals (inclusive of 9 subjects, more than 200 journals)

Providing 24-hour high-quality service

User-friendly online submission system

Fair and swift peer-review system

Efficient typesetting and proofreading procedure

Display of the result of downloads and visits, as well as the number of cited articles

Maximum dissemination of your research work

Submit your manuscript at: http://papersubmission.scirp.org/

Or contact jss@scirp.org 